\title{
Design and Fabrication of Safety Buckle using Additive Manufacturing
}

\author{
S. Kalyanakumar, S. Prakash, Nithin Mohanan, Pranav, Arshad ali
}

\begin{abstract}
Main objective is to optimize the arm component design. We have studied the existing design of the arm component and captured the initial design data. Later, we have optimized this design using honeycomb structure and found through analysis that the optimized design data is way beyond beneficial in terms of material, mass and the volume. The challenge now is to manufacture. We have recommended additive manufacturing to produce this honeycomb structured arm component, for various reasons as stated in the journal.
\end{abstract}

Keywords: Additive manufacturing, 3D Printing, Optimization, Arm in rescue equipment.

\section{INTRODUCTION}

In added substance producing advancements can be accustomed to assembling every metallic part. Indeed, even the assembling possibility of test leaves behind these procedures has been the subject of a few investigations; the leap forward in assembling is yet to be trailed by an achievement in structuring process. In this paper, in the wake of checking on the rule of added substance assembling of metallic parts, the assembling abilities and limitations of these procedures will be inspected [1]. A planning system is proposed and represented with the update of a model part. $\mathrm{AM}$ is a strategy for make which includes the joining of materials, as a rule layer-upon-layer, to make objects from 3D model information. The advantages of this strategy incorporate new structure, evacuation of tooling prerequisites, and financial low volumes [2]. It comprises of different advancements to process adaptable materials, and for a long time its prevailing application has been the assembling of models, or Rapid Prototyping.

Revised Manuscript Received on December 30, 2019.

* Correspondence Author

S.Kalyanakumar*, Mechanical Department, Aarupadai Veedu Institute Of Technology, Vinayaka Mission's Research Foundation, Deemed To Be University. Email: kalyanakumar@avit.ac.in

S.Prakash, Mechanical Department, AarupadaiVeedu Institute Of Technology, Vinayaka Mission's Research Foundation, Deemed To Be University

Nithin Mohanan, UG Students Mechanical Department, AarupadaiVeedu Institute Of Technology, Vinayaka Mission's Research Foundation, Deemed To Be University

Pranav, UG Students Mechanical Department, AarupadaiVeedu Institute Of Technology, Vinayaka Mission's Research Foundation, Deemed To Be University

Arshad ali, UG Students Mechanical Department, AarupadaiVeedu Institute Of Technology, Vinayaka Mission's Research Foundation, Deemed To Be University

(C) The Authors. Published by Blue Eyes Intelligence Engineering and Sciences Publication (BEIESP). This is an open access article under the CC BY-NC-ND license (http://creativecommons.org/licenses/by-nc-nd/4.0/)
Be that as it may, the ongoing development in applications for direct part production, or Rapid Manufacturing, has brought about a lot of research exertion concentrating on improvement of new procedures and materials[3]. This examination centers around the execution procedure of AM and is roused by the absence of socio-specialized investigations here. It tends to the requirement for existing and potential future AM venture directors to have an execution structure to manage their endeavors in embracing this new and possibly problematic innovation class to deliver high worth items and produce new business openings[4]. In light of a survey of earlier works and through subjective contextual analysis examination, we develop and test a regulating auxiliary model of execution factors identified with AM innovation, inventory network, association, tasks and methodology.

Structuring for added substance producing, It is important to distinguish their particular assembling abilities just as their assembling imperatives that must be regarded. These two points will be tended to before going to a brisk writing audit to perceive how the structuring procedure can be adjusted by AM advancements.

Because of the system of material statement, the spout must remain parallel to the vertical pivot and the part is mounted on a turning platter. This prompts availability requirements to stay away from crashes between the spout and the part. Moreover, the speed of material testimony (and stature of saved material) depends generally on the speed of the spout and on the pace of material splashed with the spout[5].

\section{PROPOSED WORK}

The greatest issue with respect to layer-based procedures concern heat dispersal. To forestall unmolten powder underneath the fabricated layer from softening while at the same time constructing, underpins must be utilized to disperse the vitality. The cutting of the parts and production of an area at a time makes the assembling of complex part, (for example, turbines edges) simpler. The filtering directions for layer based procedures are straightforwardly given by the state of the segment while, on account of DMD, the spout must be held typical to the assembling surface (building kaleidoscopic volumes doesn't require significant pre-handling). These structures have high inflexibility, low thickness, and encourage the powder expulsion. 


\section{Multiple technology approach: High variety}

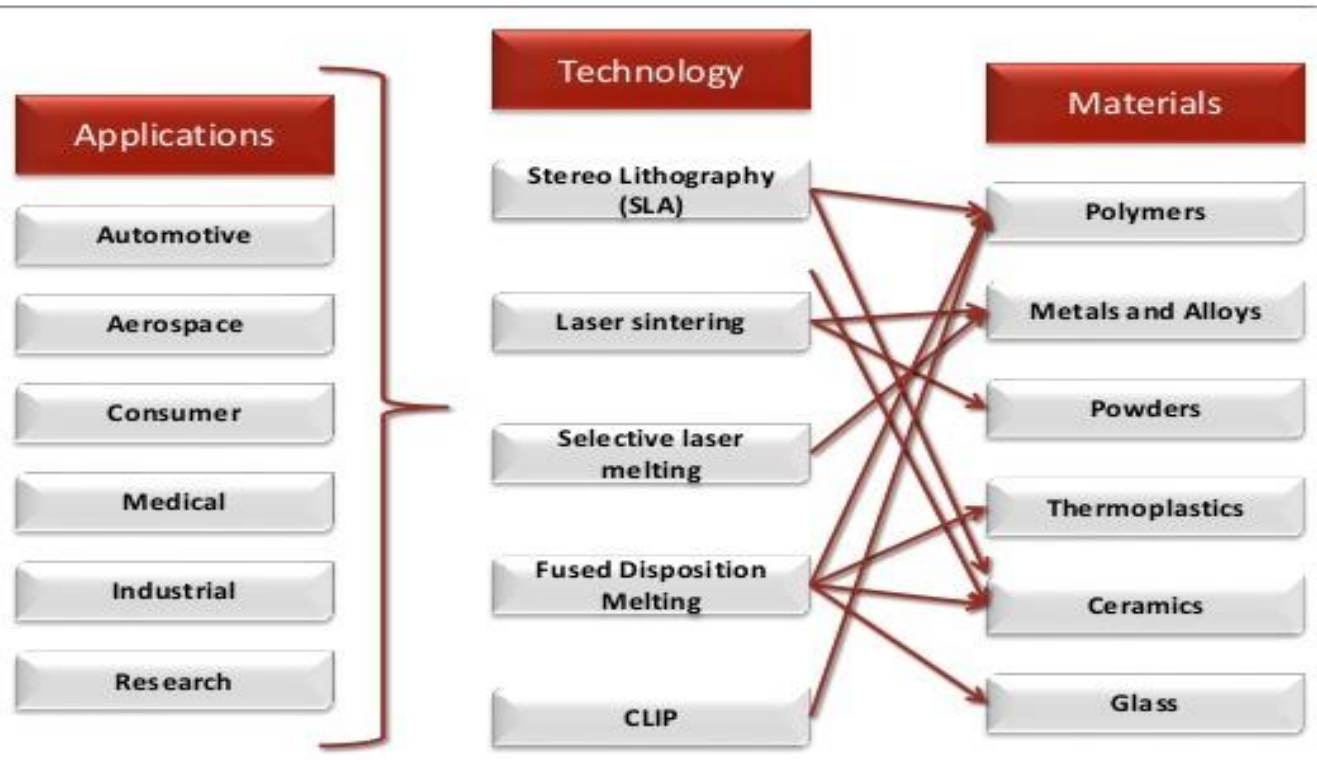

Fig. 1.Multiple technology approach

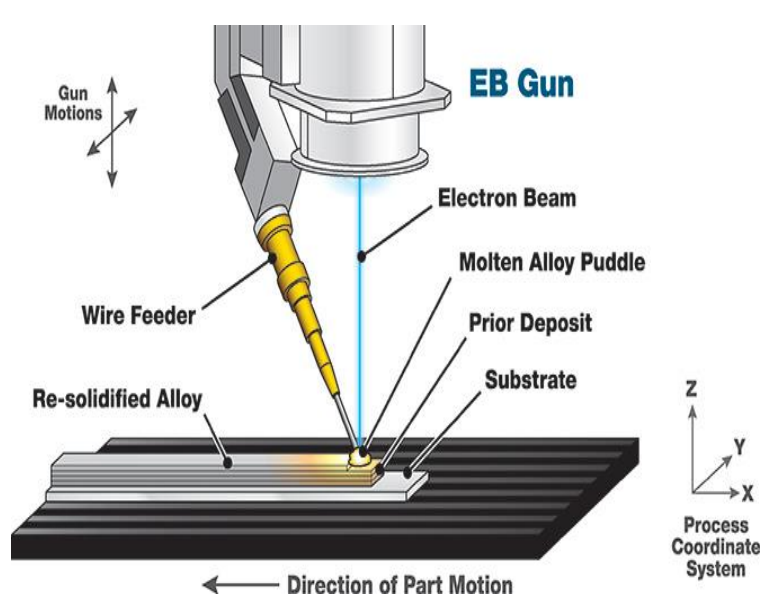

(A)

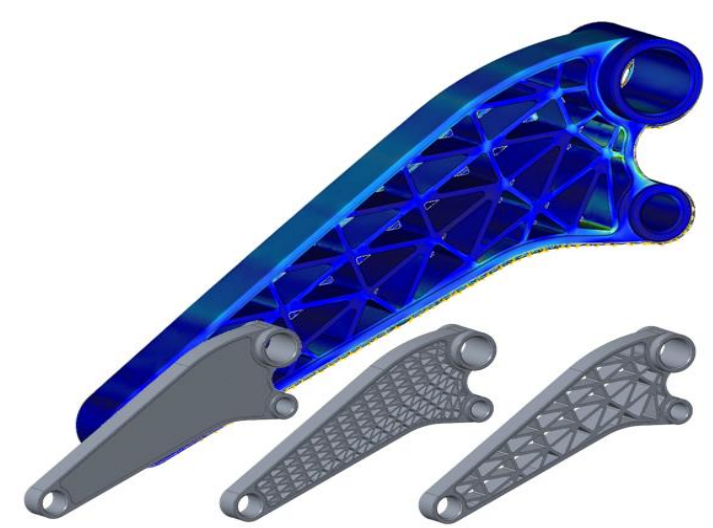

(B)

Fig. 2. Additive Manufacturing

Layer-based procedures need a plane surface to begin the production while DMD procedure can store material on a metallic substrate with complex surfaces. This ability enables this procedure to be utilized together with different procedures (it is workable for instance to manufacture turbine sharp edges legitimately onto a machined shaft) just as remanufacture or fix parts.

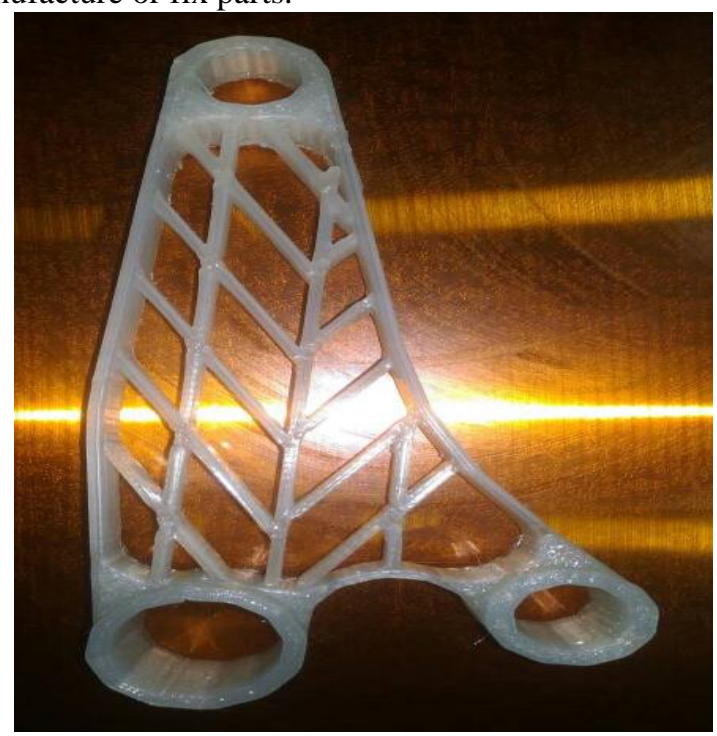

Fig. 3.Additive Manufacturing

Table I: Specification of design

\begin{tabular}{|l|l|}
\hline Initial Design & Mass: $6.02 \mathrm{Kg}$ \\
\hline Optimized Design & Mass: $3.28 \mathrm{Kg}$ \\
\hline Reduction & $46.21 \%$ \\
\hline Original Design & Material: Titanium \\
& $\begin{array}{l}\text { Tensile Yield Stress: } 139.96 \mathrm{MPa} \\
\text { Tensile Ultimate Stress: } 219.94 \mathrm{MPa} \\
\text { Mass: } 6.09 \mathrm{Kg}\end{array}$ \\
\hline Simulation Results & $\begin{array}{l}\text { Max Stress (Von Mises): } 36.23 \mathrm{MPa} \\
\text { Max Displacement: } 0.044 \mathrm{~mm}\end{array}$ \\
\hline
\end{tabular}

Published By:

Blue Eyes Intelligence Engineering 3436 \& Sciences Publication

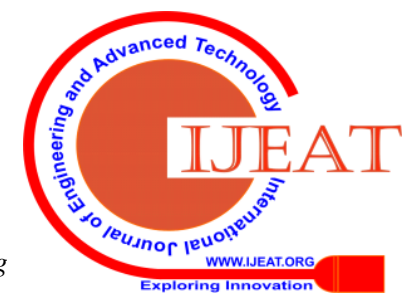




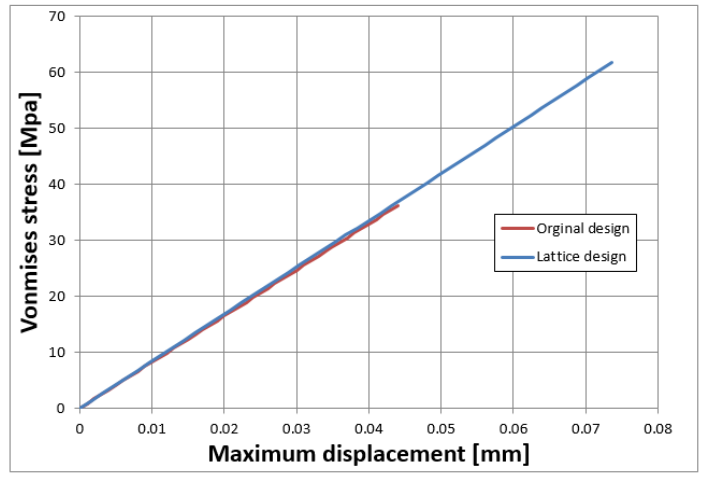

Fig. 4.Arm Original desgin

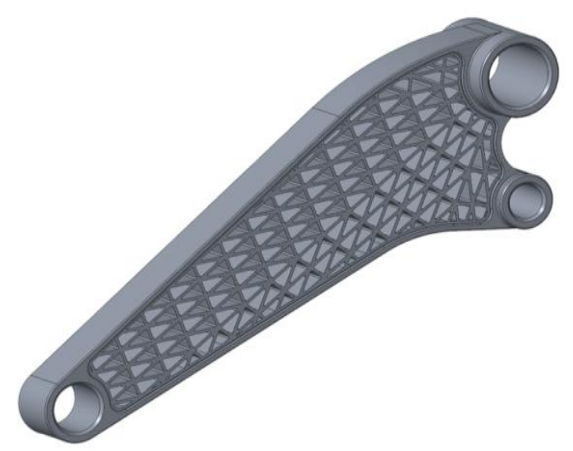

Fig. 5. Arm Final desgin

\section{Initial Lattice Design}

Material: Titanium

Tensile Yield Stress: $139.96 \mathrm{MPa}$

Tensile Ultimate Stress: $219.94 \mathrm{MPa}$

Mass: $3.48 \mathrm{Kg}$

Reduction: $42.83 \%$

\section{RESULT AND DISCUSSION}

Max Stress (Von Mises): 61.77 MPa

Max Displacement: $0.073 \mathrm{~mm}$

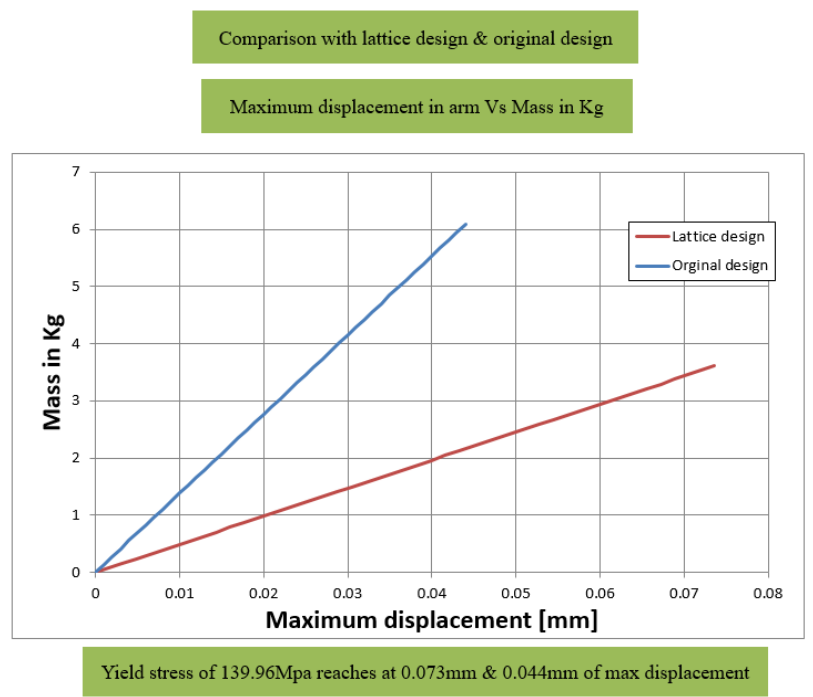

Fig. 6.Graph between Max. displacement vs Mass in Kg

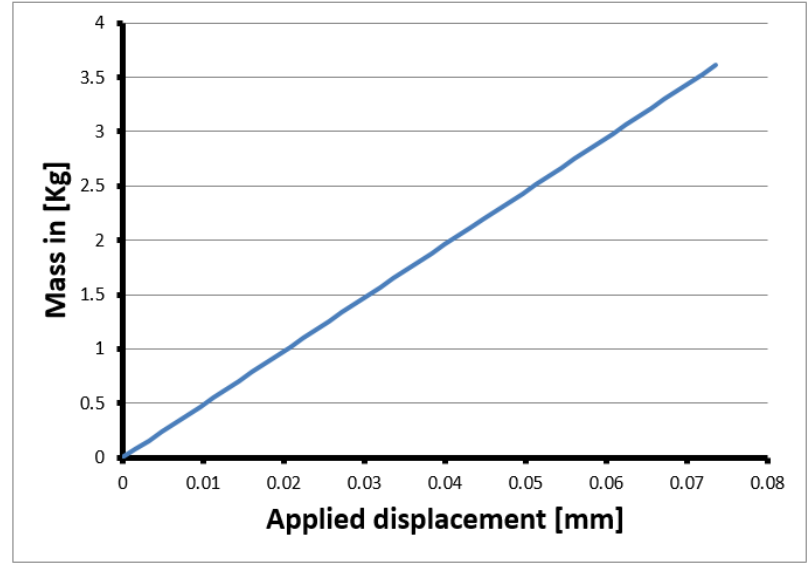

Fig. 7.Graph between App. displacement vs Mass

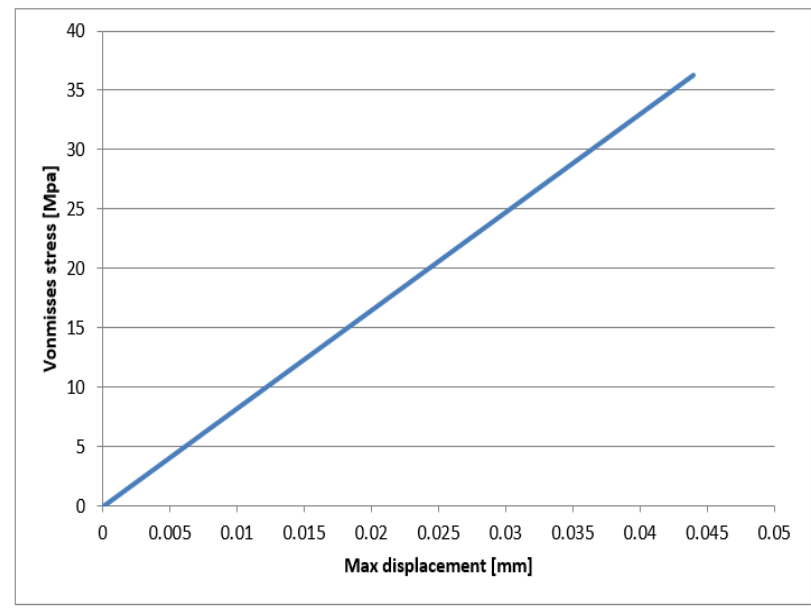

Fig. 8.Graph between Max displacement vs stress

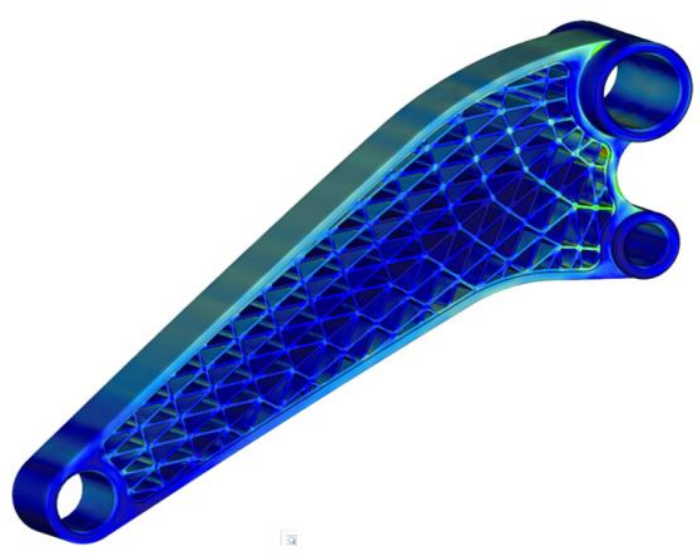

Fig. 9.Stress anlysis on arm under loading condition.

\section{A. Literature review on design for AM}

A few hub of planning for assembling have been researched in the writing. As a matter of first importance, multi-process assembling can be utilized to consolidate customary and added substance procedures to acknowledge parts without changing their shape.

Published By:

Blue Eyes Intelligence Engineering

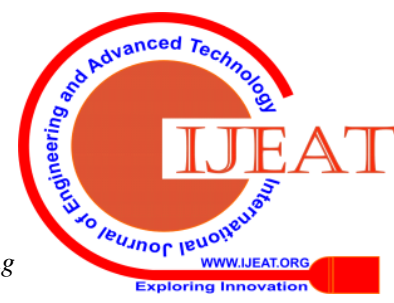




\section{Design and Fabrication of Safety Buckle using Additive Manufacturing}

A current part (effectively structured without considering fabricating requirements) is investigated to relate producing challenges, got from assembling and material limitations, to its neighborhood geometry. The part is then either made out of modules made on various procedures or with "crossover fabricating".

This paper shows that utilizing grid structure shouldn't be a target without anyone else's input since the test part made out of cross section structures charges lower than a topology advanced part. However, joining topological improvement and cross section structure demonstrates to be the ideal decision for the considered part This paper likewise manages a parametric investigation of grid structure that could be Adapted to different cases. Finally, a few papers show uses of topological improvement (TO) for added substance fabricating.

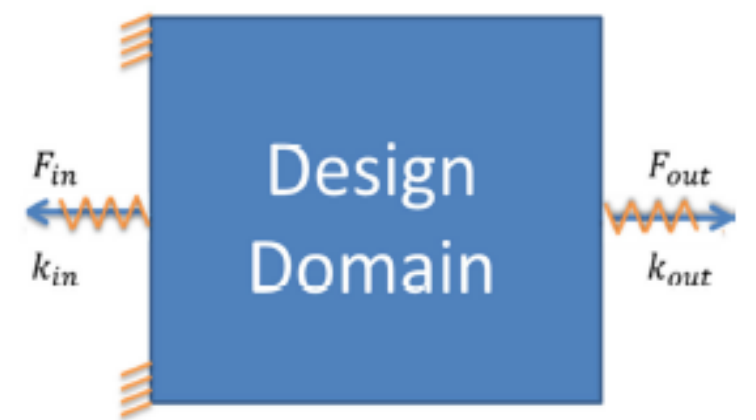

Fig. 10. Design domain

It ought to be noticed that the investigation utilized in the topology advancement was constrained to the supposition of little removals, and along these lines straight versatile examination. This can be accomplished by utilizing a little size of the applied burden. As burden size and coming about movement increments, However, the production of these streamlined materials should in any case provide a helpful purpose of correlation between 2-stage and 3-stage outcomes, despite the fact that the test redirection estimations of every example under (moderately) enormous burdens may vary from any anticipated hypothetical qualities.

2.4.1. Improvement: General plan

Due to the inverter problem, a common criterion in spatial progression and objective is to boost retard dislodging (limit relocation) in a yield port under the load $\mathrm{F}$ given in an information port. It is numerically related when everything follows (2.3) where $d$ is the nodal deletions, the unit vector $L$ yields the chance of port, $\mathrm{K}$ is the global solid network, $\mathrm{V}$ is the acceptable size of the object, Ve is the essential volume, and $\phi$ is the free structure variable vector, depicted underneath. All models were used as a baseline for the uniform distribution of the material.

\section{B. Strong Topology Optimization Formulation}

Topology utilization must include improvement to structure consistent components; it is noteworthy that arrangements can be a central focus, a situation where two strong elements are uniquely associated with one corner. One hub pivots consider lumped consistence and the exhibition of such components is overestimated with low-request limited components. Clearly, if a one-hub pivot were printed, it would momentarily bomb because of the pressure focus at a point. It was talked about in the first work that project elements can imaginably store two distracting circles while the control of a basic element size can be shown in a center. Pivot. Various analysts have explicitly handled the one-hub pivot issue with regards to the consistent inverter. Sigmund, for instance, at the same time enhanced a dissolved and widened rendition of this system is to impersonate over \& under-drawing, separately. This triggered a minute maximum of detail, and excessive erosion would trigger a detached structure, so that zero-activation would occur if one-off centers were available. While the technique effectively disposes of one-hub pivots from structures, a real "blue-print" plan, which is passed to the maker, isn't plainly distinguished. This paper receives a similar essential thought as Sigmund, utilizing a min-max plan that at the same time enhances a bigger projection and littler projection of a similar structure factors.

For this paper, we consider a basic length scale rmin set by the client to speak to the normal range of beads, and then change that drop size by legally changing the sweep $r$ used in planning.

Where Vr is the variety long scale. The subsequent min-max agreeable system improvement plan at that point takes on the structure:

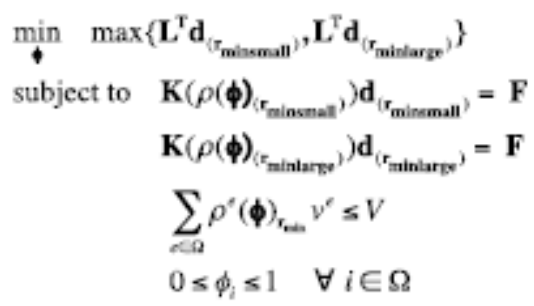

Detailing in Eq. 2.5 is about indistinguishable from Sigmund, there is an unpretentious

Distinction in accomplishing the computative irritation: Though inconspicuous, we feel the last more precisely mirrors the AM procedure. A continuation conspire on the Heaviside parameter is utilized to accomplish a quality arrangement. The beta for Rminlarge starts at 0 and is expanded by 1 for each successive step. On the other hand, Reminismal is very large and every advancement decreases by 1 until it reaches 0 . It basically expands the quality of the over \& under-storing as the calculation advances. The results of this study involved 11 consecutive attempts with $60 \mathrm{MMA}$ development cycles in each study. Given our focus on the multi-subject area of these projects, the best techniques of this powerful spatial development definition and computational tuning are not explored here. 


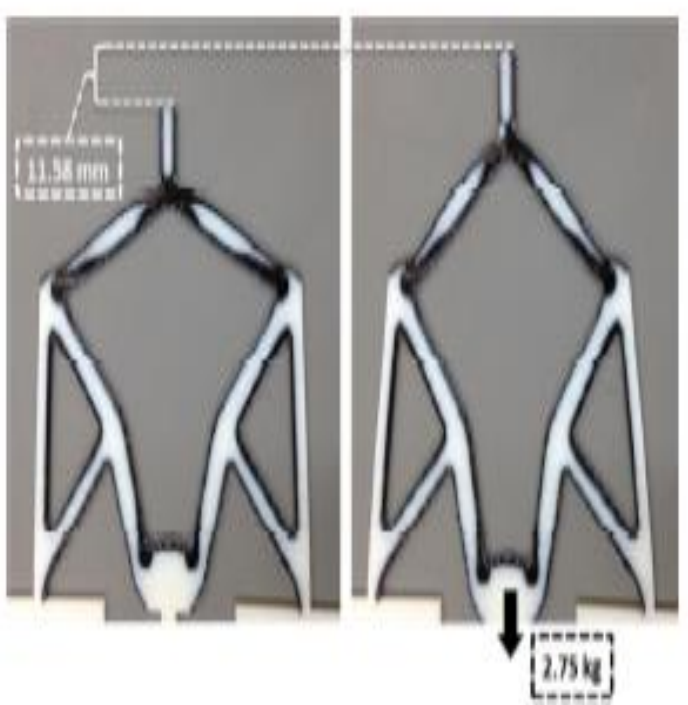

Fig. 11. Tango Black + Material shows the deflection of 3-Phase Inverter.

It is interesting to note that there is a double curve present in the decay seen in the figure, perhaps $60 \%$ of the time, or perhaps the same as the case.

\section{CONCLUSION}

With the assistance of added substance producing innovation, we can accomplish the ideal enhanced structure and quality of arm segment. Added substance producing advancements have been invited in all enterprises due to the likelihood to fabricate lighter structures to diminish weight. Added substance producing has made work simpler for planners, who currently can print the 3D models for whatever intricate shape for a common undertaking they have as a main priority. What's more, examines are looked into which were about the quality of items made in added substance producing forms.

\section{REFERENCES}

1. StephenMellor, LiangHao, DavidZhang "Additive manufacturing: A framework for implementation" International Journal of Production Economics, Volume 149, March 2014, Pages 194-201.

2. S. Ashley, "Rapid prototyping systems," Mechanical Engineering, vol. 113.

3. T. Wohlers, "Additive Manufacturing Advances," Manufacturing Engineering, vol. 148.

4. T. Grimm, User's Guide to Rapid Prototyping, Society of Manufacturing Engineers, 2004.

5. K. Cooper, Rapid Prototyping Technology, Marcel Dekker, 2001.

\section{AUTHORS PROFILE}

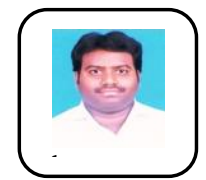

S. Kalyanakumar, Assistant Professor Gr-II Mechanical Department, Aarupadai Veedu Institute Of Technology, Vinayaka Mission's Research Foundation, Deemed To Be University. Having 11 years of experience. Life member in ISTE and ENFUSE

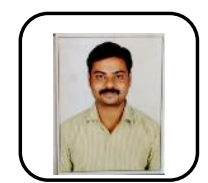

S. Prakash, Assistant Professor Gr-II Mechanical Department, Aarupadai Veedu Institute Of Technology, Vinayaka Mission's Research Foundation, Deemed To Be University.

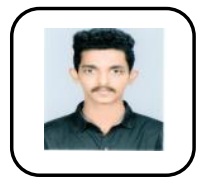

Nithin Mohanan, UG Student Mechanical Department, Aarupadai Veedu Institute Of Technology, Vinayaka Mission's Research Foundation, Deemed To Be University.

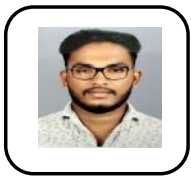

Pranav, UG Student Mechanical Department, Aarupadai Veedu Institute Of Technology, Vinayaka Mission's Research Foundation, Deemed To Be University.

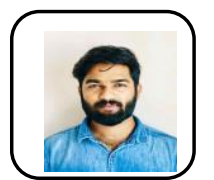

Arshad ali, UG Student Mechanical Department, Aarupadai Veedu Institute Of Technology, Vinayaka Mission's Research Foundation, Deemed To Be University. 